\title{
THE WORLD WIDE WEB AND THE DILUTION OF THE CHINESE LANGUAGE
}

\author{
Weiping Zheng \\ Dept. Information Systems, \\ Shenzhen University \\ China
}

\begin{abstract}
It is widely assumed and frequently asserted that the rapid developments of the $W W W$ or the Internet have brought dilution to the cultures and languages of non-English speaking communities. This paper explores some virtual Chinese communities on the Internet for their new habits of using the Chinese language. The research was conducted during October 1997. The prime objective was to identify how Chinese people talk to each other in this digital age using their native language. Some significant changes have already happened. One unexpected finding was that more mainland Chinese people tend to give up their native language on the Internet.
\end{abstract}

\section{INTRODUCTION}

WWW and the rapid development of the Internet have brought great changes in our society. The first page of the $21^{\text {st }}$ century has been opened. People around the world now can greet each other like villagers. Geographical boundaries disappeared gradually during globalisation. New technologies have created benefits for some share-holders. They also created worries for some people. People in the alphabet-writing countries other than English now start to worry about the invasion of foreign cultures, foreign languages. As one of the successful pictographic writing systems, the Chinese language has survived for thousands of years. Will it survive the impact brought by the Internet? How and to what extent has it been affected by the WWW? Based on virtual Chinese citizens, this paper tries to answer this question.

To look at the impact brought by the WWW, we have to look at computers first; that is, who is using a computer in China? Currently, to own a computer is still a dream to most mainland Chinese people. Table 1 shows the numbers (in million items) of the Desktop PCs sold in mainland China published by the Ministry of the Electronics of China in the three years 1995-97. 
Table 1. Desktop PCs sold in mainland China, 1995-97

\begin{tabular}{|l|c|c|c|}
\hline & 1995 & 1996 & 1997 \\
\hline Desktop PCs & 1.2 & 2.1 & 3.0 \\
\hline
\end{tabular}

Though it is increasing rapidly, the number is still small compared to the population. Most of these PCs went to universities, governments and organizations, only a few went to private homes. So the most computer literate people are those who graduated from the Universities in last twenty years. They are facing the impact of the Internet before other people. In other Chinese-resident areas like Hong Kong and Taiwan, computers are more popular. Some of those mainland Chinese university graduates are now studying in US and Australia. Talking about the impact of the Internet, we must take all these people into consideration.

\section{METHODOLOGY}

The direct and simple way to collect information is to send out a questionnaire. But according to previous research, the response rate can be poor. Tse et al (1995) found that even in an internal e-mail survey, the return rate was 4 percent compared to 27 percent for a conventional mail survey. Comley (1996) came to a similar conclusion. Smith (1997) found that HTML based form obtained low return rate. So it is almost impossible to do data collection using a survey questionnaire, no matter whether it is an email survey or a mail survey of surfing net citizens. But there are websites where those Chinese net citizens voluntarily take part. Some of these websites attract tens of thousands of surfers every day. They greet each other, post an article, start a discussion, and gradually develop a culture that is abided by following net citizens. These websites are Chinese BBS forums around the world. They have all the new words, expressions, habits that were introduced by the internet and that differ from the original usage of the Chinese language. By looking at some popular Chinese forums, and doing some simple calculations, the researcher found many interesting results. Most forums outside mainland China are political forums either related with the topic of the hand over of Hong Kong or the reunification of China, or the political and economic development in mainland China. The following seven fora simply named from A to $G$ are the objects that were chosen to be analyzed for the research reasons above.
A: technological forum in mainland China
B: general topic forum in a mainland Chinese University
C: $\quad$ general topic Chinese forum in Hong Kong
D: cross-strait topic Chinese forum in Taiwan
E: general topic Chinese forum in USA
F: technological Chinese forum in US
G: general topic Chinese forum in Australia. 
The main criteria of choosing a forum is its popularity among net surfers, specifically the number of hits it receives everyday.

Most fora have a similar HTML format of their postings:

- $\quad$ Title - Author

- Follow-up Title - Follow-up Author.

A net surfer would publish his ideas with a title and an author name linked with the homepage of the forum, other people may follow his topic if hinterested. So this kind of forum is like a virtual village. Villagers are the same as everywhere, some are quiet, some are noisy. Their post shows their new habits of using native language in the virtual village. Exploration of how people post their titles and author names will certainly reveal the trend of using their native language within these virtual Chinese communities. On October 1997 and November 1997, two calculations were made, the results were averaged.

\section{DEFINITION OF 'DILUTED CHINESE LANGUAGE'}

A title consisting of one or more English words, or the whole title in English, would be considered as 'diluted Chinese language'. Terminology like 'Re: ' to start a follow-up posting would be ignored because they can be simply changed to relevant Chinese terminology by the administrators.

Likewise, an author pen name consisting of one or more English words, or using phonetic alphabets, would also be considered as 'diluted'.

\section{DISCUSSION OF RESULTS}

The results were calculated from hundreds of postings in these forums. The percentage of 'diluted' titles and author names ware shown in Table 2.

Table 2. Diluted titles and author names

\begin{tabular}{|l|c|c|c|c|c|}
\hline \multicolumn{2}{|c|}{} & \multicolumn{2}{c|}{ Title } & \multicolumn{2}{c|}{ Author } \\
\hline Forum & Total & Diluted & Rate(\%) & Diluted & Rate(\%) \\
\hline A & 132 & 49 & 37.1 & 78 & 59.1 \\
\hline B & 102 & 26 & 25.5 & 69 & 67.6 \\
\hline C & 136 & 52 & 38.2 & 90 & 66.2 \\
\hline
\end{tabular}




\begin{tabular}{|l|c|c|c|c|c|}
\hline $\mathrm{D}$ & 90 & 2 & 2.2 & 38 & 42.2 \\
\hline $\mathrm{E}$ & 656 & 34.5 & 5.3 & 110 & 16.8 \\
\hline $\mathrm{F}$ & 338 & 20 & 5.9 & 67 & 19.8 \\
\hline $\mathrm{G}$ & 222 & 75 & 11.36 & 115 & 28.6 \\
\hline
\end{tabular}

\subsection{Title vs. Author name}

More people tend to give up their Chinese names when they are posting an article rather than use a diluted title. In this case the forum is very much like a virtual village. In the forum, a person is recognized or remembered by his or her pen names. Any kind of name that he can think of can become a pen name when he starts to talk with other people. While posting an article, the desire to communicate with other virtual citizens makes him use purer original language titles. This makes the title the main carrier of the message, rather than the author name. The author name is then treated as a code only, rather than the vivid person.

\subsection{Mainland vs. other regions}

More mainland Chinese and Hong Kong Chinese tend to use diluted language in these forums. As the Chinese language is one of the pictographic languages, so an individual has to be well-trained before using a computer freely on the Internet. The cultural revolution caused the suspension of higher education. So now most mainland Chinese net surfers are students who majored in computer science or IT technicians, simply because they have access to computer facilities and training opportunities. They tend to have more technological words and expressions that have not been officially translated into the Chinese language. For example, the word 'Internet' was officially translated into Chinese in the middle of 1997, several years after it had been used by lots of students and technicians.

\subsection{The limitation of this paper}

It is obviously not a complete analysis about the current situation of using the Chinese language on the World Wide Web. The language style in these virtual villages may be changing all the time. But one thing is certain, the scenario of using diluted Chinese language is very common on the Web. 


\section{ROLE OF THE GOVERNMENT}

It is interesting to look at the role of the government. If China wants to compete with other countries, China must promote the usage of foreign languages, especially English, to promote the level of IT. As commented by one participant to a Beijing IT conference (Don 1997)

"...By the time you finish the translation, IT maybe obsolete, ..."

So the government will be in a dilemma: promoting the use of English and watching the diluting of the native language. At this stage the information exchange between China and western countries is one way. The WWW brings new emerging words and ideas to Chinese people in seconds. People have to use them before the government issues an official translation. So in the near future, more and more people will use more and more diluted Chinese language. If the language is diluted, the culture will be next, then the people. The Japanese language has been changed a lot in the last hundred years, so have the Japanese people. We have survived successfully during industrialization. What happens to the Chinese language during globalization? This paper has tried to provide an answer.

\section{REFERENCES}

Comley, P. (1996) The use of the Internet as a data collection method.

Available electronically from http://www.sga.co.uk/esomar.html

Don T. (1997) Chinese Language hampers China IT development." Nov.1997 IDG China. Available electronically from http://www.idgchina.com/idgnews.htm

Smith, C. B. (1997) Casting the Net: Surveying an Internet population.

Available from http://www.usc.edu/dept/annenburg/vol3/issue1/smith.html\#rref1 1

Tse, A. C. B., Tse, K. C., Yin, C. H., Ting, C. B., Yi, K. W., Yee, K. P., \& Hong, W. C. (1995) Comparing two methods of sending out questionnaires: E-mail versus mail. Journal of the Market Research Society 1995 37(4) 441-446. 